\title{
The Motivation Model Design of Knowledge-intensive Enterprise Talents
}

\author{
Bo Zhang \\ Mudanjiang Normal University, School of Economics and Management, Heilongjiang, \\ Mudanjiang157011 \\ huner2011@foxmail.com
}

Keywords: Knowledge-intensive, Enterprise, Talent incentive model

\begin{abstract}
The knowledge-intensive enterprises intend to motivate knowledge workers effectively through the limited enterprise resources. First of all, the knowledge-intensive enterprises must establish a correct incentive concept, which is based on the systematic knowledge workers incentive theory guidance; then put incentive into reality, that is, establish the enterprise incentive system for knowledge workers system, formulate specific incentive methods, which is based on the analysis of the workers incentive mechanism, and the support and guidance of obtaining the specific knowledge workers incentive model. Only by designing correct and effective knowledge workers incentive model can the knowledge-intensive enterprises have ways to realize the rational allocation of limited incentive resources, use the limited resources most effectively, motivate knowledge workers sufficiently, thus this paper studies and designs the knowledge workers incentive model.
\end{abstract}

\section{Knowledge Workers Motivation Model Design based on Stock Options}

The stock option incentive in a narrow sense refers to the current ESO (ESO: Executive Stock Options) prevailing in western countries. According to the practice of implementing ESO pattern in western countries, it can be seen that it did motivate managers and alleviate the agency problems. And some scholars think that as a micro institutional factor, ESO's contributions cannot go unnoticed for consecutive economy growth miracle in America since the 1990s.

The ESO pattern made success in large listed enterprises, but if it can be applies to booming knowledge-intensive enterprises to solve the problem of insufficient incentive resources. First of all, from the point of definition, ESO pattern strictly limits its application range in the listed enterprises, and it must be based on the developed capital market. Although there are large listed enterprises such as Microsoft, Cisco, most of the knowledge-intensive enterprises are unlisted SMEs, and their countries may not have the mature capital markets, for example, China's capital market is still in an early stage of development, and relevant laws and regulations implement strict rules for issuing new shares and stock repurchase. Second, the incentive object of ESO pattern is only confined to senior management, such as CEO, CTO, which has many limitations, because the development of the knowledge- intensive enterprises need the joint effort from knowledge teams, what's more, the whole role of knowledge workers groups is even bigger than management personnel, thus they also need to get the long-term incentive. In view of the above situation, the knowledge-intensive enterprises must have generalized understanding of stock option incentive, that is, absorb the internal essence of ESO, and reform its implementation model, so as to broaden its coverage.

Mathematical Motivation Model of Stock Option for Knowledge Workers. The motivation model of knowledge option can be expressed by digital method as follows:

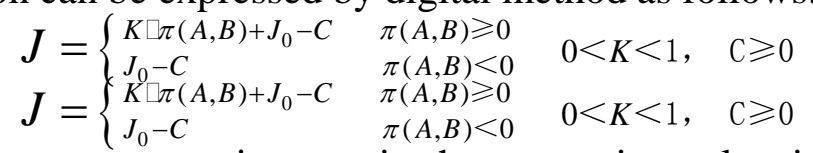

Here, $\mathrm{J}$ is the incentive compensation, $\pi$ is the enterprise value increment from enterprise growth and accumulated profit within the period of validity of option, which is the function of effort level A and external influence factors B for incentive object (knowledge workers); under the mode of stock option, $\pi(\mathrm{A}, \mathrm{B})$ is reflected by securities market, manifests as the product of the gap between the market price and the final price of each share and the total share when validity ends. For the internal profit center in non-listed enterprises and business division, $\pi(A, B)$ can be shown 
by internal information, that is, investigating the change of net assets per share. $\mathrm{K}$ is the proportion of the underlying stock option in the share option, while $C$ is the option premium. If the option is granted freely, then $\mathrm{C}=0 . \mathrm{J}_{0}$ is the basic reward outside the options. The function appears two kinds of expressions due to the interference factor $\mathrm{F}$, and it may lead to $\pi(\mathrm{A}, \mathrm{B})<0$, given the reasonable risk aversion of knowledge workers, it can allow them to abandon the option exercise, which can limit losses above $\mathrm{C}$ (option premium); on the other hand, when $\pi(\mathrm{A}, \mathrm{B})>0$, $\mathrm{J}$ increases without upper limit with $\pi(\mathrm{A}, \mathrm{B})$. Such risk distribution is undoubtedly a significant motivation for knowledge workers, solve the trouble from behind as well, making them concentrate on work and promote the knowledge innovation.

\section{Knowledge Workers Motivation Model based on Psychological Contract}

Research on the psychological contract development. In the 1980s, the organizational behavioral scientist, Mcnier, thought that the employment relationship between labor and the capital has two types: relationship type and transactional type. Here, the relational type refers to the long time employment relationship with unclear task, which is characterized by mutual support from both sides, and high employee trust and loyalty; on the contrary, the transactional type is a short time one with clear task, and employees' organizational commitment is not high. On this basis, Denise Luther develops a two-dimensional model of the concept of psychological contract between individual and organization [39] (as shown in Fig. 1).



Fig. 1 Concept Model of Psychological Contract

First, the transactional type psychological contract model. This is a short-term employment relationship with clear task, focusing on economic transactions. Both sides shoulder relatively limited responsibility, and the organization does not have long-term employment commitment for employees.

Second, the transitional type psychological contract model. This is a short-term employment relationship with unclear task. It generally appears during the period of organizational structure changes or transition, and the conflicting employment relationship can be formed easily.

Third, the level type psychological contract model. This is a kind of dynamic and open employment relationship, and conditions good economic performance and good career development. Both sides pay close attention to the development of each other, and the organization rewards employees based on the performance.

Fourth, the relationship type psychological contract model. This is a long-term and open employment relationship based on mutual trust and loyalty of both sides, and the relationship between the employees reward and their performances is loose, mainly because the employee is an organic part of the organization.

Motivation Model Design based on Psychological Contract. In the era of knowledge economy, the powerful position of knowledge workers determines that the establishment of the psychological contract must be centered on knowledge workers. Only when knowledge workers think the organization has promised to give them (by their corresponding contribution) reasonable and fair wages, promotion opportunities, professional training, rich work and flexible welfare, etc., in turn, 
workers will be willing to contribute their energy, time, knowledge, and sincerity to organizational development. Promise realization and fair rewards are the key to form effective incentive. The following is the knowledge workers motivation model based on the psychological contract (see Fig. 2) (the solid lines show the causal relationship, while the dotted lines show the cyclic feedback).

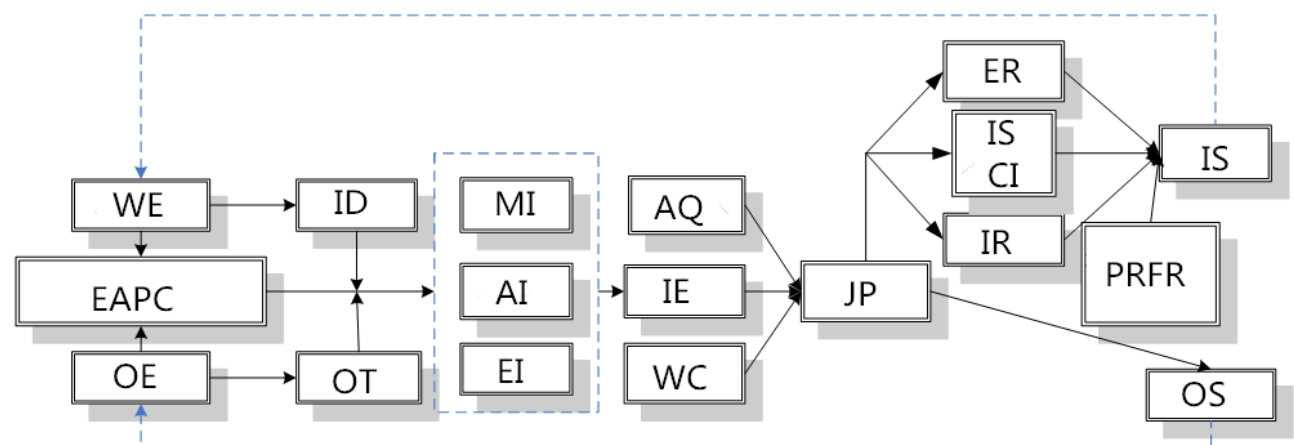

Fig. 2 Knowledge Workers Motivation Model based on the Psychological Contract

Note: WE: worker expectation, ID: individual demand, EDPC: establishment and adjustment of psychological contract, OE: organization expectation, OT: organization task, MI: material incentive, AI: achievement incentive,EI: emotion incentive, AQ: ability and quality, IE: individual efforts, WC: working condition, JP: job performance, ER: external reward, IS: interpersonal support, CI: cultural identity, IR: internal reward, IS: individual satisfaction, PRFR: promise realization and fair rewards, OS: organization satisfaction

The motivation model based on psychological contract allows the knowledge workers motivation to convert from a single incentive mechanism based on economic contract into the incentive mechanism combining psychological contract with economic contract. The psychological contracts in the model include three dimensions, namely the transaction dimension, relational dimension and the team member dimension.

\section{Conclusion}

The motivation model based on psychological contract shows that the incentive of knowledge workers is a process with dynamic cycle. Under the interactive function of "staff expectation" and "organization expectation", the original content of "psychological contract" is formed, and taken as a starting point, through the comprehensive application of material incentive, achievement motivation and emotional incentive, the "individual effort" can be caused to obtain job performance, achieve the goal of organizations and employees; finally through the evaluation and feedback of "personal satisfaction" and "organizational satisfaction", the adjustment of psychological contract can be achieved, consequently, the interaction between knowledge workers and organization can be realized.

\section{References}

[1] Edward. E. Lawyer. Pay and Organizational Effectiveness: A Psychological View. New York: McGraw - Hill, 1997.

[2] William A. Schliemann. Major Trends in Employee Attitudes Toward Compensation, in Schliemann (ed.), Managing Human Resources: 1983 and Beyond, Princeton. N. J:Opinion Research Corporation, 1983.

[3] Richard E. Walton. Establishing and Maintaining High Commitment Work Systems, in J. Kimberly and R. Miles (ed. ) Organizational Life Cycle. San Francisco: Jossey Bass, 1980.

[4] Argyris C. Understanding organizational behavior. London: Tavistock Publications, 1960. 
[5] Schein E H. Organizational psychology. 3rded. Englewood Cliffs, NewJersy: Prentice-Hall, 1980.

[6] Robinson S L. Trust and breach of the psychological contract. Administrative Science Quarterly, 1989.

[7] Roseau. Is the psychological contract worth taking seriously. Journal of Organizational Behavior,2001. 